\title{
Tackling the Issue of Student Debt Through Data Sonification and Musical Scores
}

\author{
Zach Buckley \\ Illinois State University \\ Normal, Illinois, USA \\ zwbuckl@ilstu.edu
}

\begin{abstract}
The issue of student debt is an invisible but ever-present aspect of the college experience within the United States. While this debt can sometimes be deemed necessary to cover the increasing costs of attending college, the risks are high with just over $10 \%$ of borrowers defaulting within three years of receiving a loan. Research has shown that many students are unaware of the size of the loan they have taken out to cover expenses and that some students are even unaware they have taken loans out to begin with. This implies that there is an opportunity to present new ways of engaging with student populations about the risks regarding student loan debt. I will present a paper on my work of art "A Good Education (Explorations in Data and Music)" that discusses the design process, the aesthetic issues surrounding the translation of data into musical scores, and the recording and exhibiting of this body of work. The work is comprised of three musical scores and accompanying audio recordings. Each score explores a different set of data with varying compositional methodologies and instrumentation. I will also discuss the challenges of presenting this body of work, the outcomes, and audience response over the duration of the exhibition.
\end{abstract}

Music composition. Student debt. Data sonification.

\section{INTRODUCTION}

"A Good Education (Explorations in Data and Music)" is a collection of three short music compositions designed to explore the economic prospects of students over the course of their education. I have translated data sets into scores and then recorded three different student ensembles as they translated the scores into a performance. With this work, I ask the question, "can non-traditional means of expressing data, such as art and music, raise awareness of the risks and outcomes of student loan debt while proving to be of sufficient aesthetic merit?' The work is a triptych comprised of three short musical pieces. "The Average Student Loan Borrower in 7/4" attempts to express how borrowers will statistically have fewer resources available to them over the course of their lifetimes depending on the amount of money they borrow. "Tuition Rises, Wages Stagnate" is an improvised string quartet that documents the price of tuition at private and public universities, the minimum wage, and early career salaries over a 30 -year period. Finally, "Nominal vs Actual Minimum Wage" details the nominal value of the minimum wage since the 1930s against its actual buying power adjusted for inflation.

\section{BACKGROUND}

The issue of student debt is an invisible but everpresent aspect of the college experience within the United States. In total, 44 million people owe a collective $\$ 1.5$ trillion dollars with each individual shouldering an average of just over $\$ 37,000$ (Board of Governors of the Federal Reserve System (US) 2019). While this debt can sometimes be deemed necessary to cover the increasing costs of attending college, the risks are high with just over $10 \%$ of borrowers defaulting within three years of receiving a loan (U.S. Department of Education 2019).

I've always been perplexed and fascinated that student debt has become a social norm in the United States. While the history and political climate that could create a situation as widespread as the student debt crisis is worthy of discussion, it is an undertaking far beyond the scope of this paper. Instead, once I reached a stage in my education that required me to take out student loans of my own, my primary interest shifted to the idea of being 'in' debt. The language of being 'in debt' implies a sort of metaphorical 
encompassment where the borrower has begun to occupy, and indeed embody, a new space separate from their pre-debt existence. It was this line of thinking that proved to be the impetus for "A Good Education (Explorations in Data and Music)."

The goal of this project, ultimately, was to raise awareness of and facilitate conversation around the student debt crisis amongst visitors to University Galleries of Illinois State University. This goal was achieved by transforming the Galleries sonically into a space where every visitor would experience this embodiment, and by presenting the data in a way that the visitors may not have experienced before. The work was entered as a part of the Student Annual exhibition, which sees some of the highest attendance numbers for the whole year. The opening reception consistently draws over 300 people, the majority of whom are students, family members, and university faculty and staff - people who are all, at some level, connected to the student debt crisis.

\section{CONTEXTUAL CHOICES}

My design process for this work was largely informed by the knowledge that, if juried in, it would be exhibited at University Galleries of Illinois State University. This space is a contemporary gallery space spread out over the bottom floor of a public transportation depot in Normal, Illinois. The space includes a large atrium, four galleries, and a wall of windows that provides impressive access to the community. Considering that my goal was to create an artwork that explored this embodied feeling of indebtedness, I found it proved crucial to anchor everything within the context of the exhibition space. For me, this meant that it would be best to create specifically around the constraints and opportunities provided by the architecture and amenities of University Galleries. The space is just over $7500 \mathrm{sq}$. ft. and is divided up into several rooms (Figure 1). This detail was important to me as the metaphor of being 'in debt' is spatial in nature; it alludes to a physicality of containment. In this regard, it can be viewed in a similar vein as the very tangible experience of being in doors. By superimposing the metaphor of being in debt with the physical experience of being in doors I could view the entirety of University Galleries as the indebted space.

By building this work from the position that University Galleries itself would exist as the indebted space granted me a conceptual freedom in how I approached the subject matter. If the space within University Galleries was meant to be experienced as an embodiment of debt it, required the work to be ever-present with a person as they experienced the space. Taking that into consideration, a visual work that existed everywhere a person went within the Galleries would prove to be difficult logistically due its size division of space and still may not provide the desired embodied experience. Sound, however, could easily be an omnipresent experience within the space - one that people would experience constantly as they moved throughout the Galleries as the space has an integrated sound system. While the conversation around phenomenology has been largely anchored in relation to our experiences within a physical space (MerleauPonty 2002), it has been suggested that the idea can extend to sound and music and that a person can be not only subject and object of the world around them but also one that hears and is heard (Corness 2008).

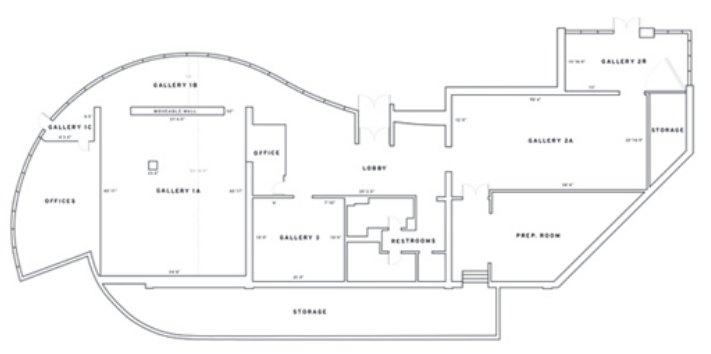

Figure 1: This is an architectural floorplan of University Galleries of Illinois State University (University Galleries 2019).

\subsection{Aesthetic issues concerning sonification}

The second major goal of this project was to raise awareness of and facilitate conversation surrounding the student debt crisis amongst the Illinois State University community. The average student at Illinois State University borrows a little more than $\$ 25,000$ over the course of their education (Illinois State University 2019) and recent studies have even suggested that some of these students may not even know they've taken loans out (Brookings Institute 2019). Taking this information into consideration, I wanted to try and present the data in a fashion that would resonate with the University community and visitors to University Galleries. To do so, I chose to visually display the interpreted data as musical scores and to loop recordings of Illinois State University students performing the 'data' of the musical scores.

In choosing to approach the data as source material for music to be performed by musicians, it granted me the freedom to make artistic and aesthetic choices that I felt were in line with the vision of the project. In this regard, I believe it to be more accurate to call the finished work a musical translation of the data as opposed to a strict sonification of the data. While sonification in its simplest definition is the "use of non-speech audio 
to convey information" (Kramer et al. 2010), and "A Good Education (Explorations in Data and Music)" certainly aims to do so, that isn't the primary function of this project. The difference can best be explained by examining the expanded definition offered:

"Sonification is the transformation of data relations into perceived relations in an acoustic signal for the purposes of facilitating communication or interpretation." (Kramer et al. 2010)

The word transformation within this definition implies that there is a direct, quantifiable relationship between the data and the sound being produced. A key aspect of that process is that the transformation is systematic, and the sound is reflective of objective properties or relations in the input data (Hermann 2008). So while "A Good Education (Explorations in Data and Music)" is the use of non-speech audio to convey information, and therefore a sonification in the simplest sense of the word, I will continue to describe the process as one of musical translation because the process was anchored in an artistic interpretation of the data and not a systematic transformation.

\section{COMPOSITION AND DESIGN CHOICES}

"A Good Education (Explorations in Data and Music)" is a musical triptych that sonically examines the historical buying power of the minimum wage, the relationship between rising tuition and wages, and the post-college economic outlook of student loan borrowers in the form of recorded performances by student ensembles. By exploring these data sets that are influencing factors on the student debt crisis as opposed to seemingly more direct data like the amount of student borrowers in default, I hoped to create more room for conversation and personal interpretation amongst the visitors to University Galleries.

The visual component of the piece was comprised of all three scores written on the entry wall of the gallery space in permanent marker (Figure 2). This was done in part to make the work seem as unassuming and approachable as possible to gallery visitors. By using permanent marker, I not only wanted to invoke the feeling of indelibility that comes with debt, but also to give a physicality to the expression "the writing is on the wall."

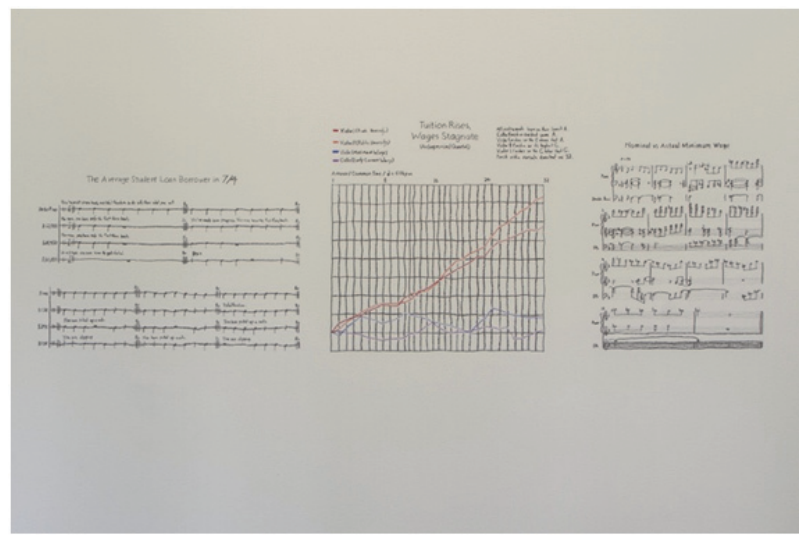

Figure 2: Installation view of "A Good Education (Explorations in Data and Music)"

The music was diffused within all three galleries and the lobby through the overhead sound system. By using the Galleries built-in, overhead sound system it gave the music a sense of being everywhere at once and; while the speakers could easily be seen overhead the sound still had a sense of placelessness within the space. From anecdotal evidence as conversations overheard in the gallery spaces, I believe this placelessness experience was achieved.

\section{1 "The Average Student Loan Borrower in 7/4"}

The first section of the work, "The Average Student Loan Borrower in 7/4" is a largely improvised quartet where each of the four musical voice represents a student graduating college debt-free, with $\$ 12,000$ in debt, $\$ 28,950$ in debt, and $\$ 50,00$ in debt. This work was inspired by a report issued by GoodCall (2019) that sought to quantify the post-graduation effects of student loan borrowers. Homeownership, marriage, retirement, and salary can all be severely affected by student debt. The more debt a student has, the higher the likelihood they will have fewer resources available to them over the course of their life. To musically explore the idea that increased debt correlates to fewer resources, I scored the piece only with quarter notes and rests not as a way of providing a dictated rhythm but instead as an indicator of where the performer is allowed to play and where they are not. In this regard, it creates a metaphor in which the performer has fewer musical resources with which to achieve their musical goals. The three musical lines highlight varying degrees of debt are sharply contrasted by the part representing the debt-free student, which has no limitations, placed on it and may freely improvise for the whole duration of the piece. 
The work was composed in $7 / 4$ as a loose representation of a week and therefore tying the piece to a greater sense of time as a whole being the other mitigating factor aside from the amount of debt each musical line represented. The ensemble in the recording is a percussion ensemble, however, the piece has no set instrumentation or key. It can be performed by any group of musicians and this was done to further express the dominance of the unrestricted, debt-free line. The particular ensemble that was recorded for the exhibition was comprised of timpani, congas, agogo, and marimba.

\section{2 "Tuition Rises, Wages Stagnate"}

The second section of the work, "Tuition Rises, Wages Stagnate" is a fully improvised string quartet that compares the minimum wage, early career salary, public university tuition, and private university tuition over the course of 30 years. For the score, the players are provided a slightly modified version of a graph (Figure 3 ) depicting this data. The only traditional notation provided to the ensemble is a key signature, a tempo, bar lines, starting notes, and ending notes. To get from the starting note to the ending note, each player plays a line on the graph and follows its trajectory musically. The result of this notation is often a musically dissonant performance that highlights the radical disconnect between wages likely of current students and recent graduates with the evergrowing cost of tuition. The piece reaches a climax where the violins are separated from the lower two voices by a span of several octaves that highlights audibly the absurd notion that wages, and tuition can continue to coexist in their current relationship.

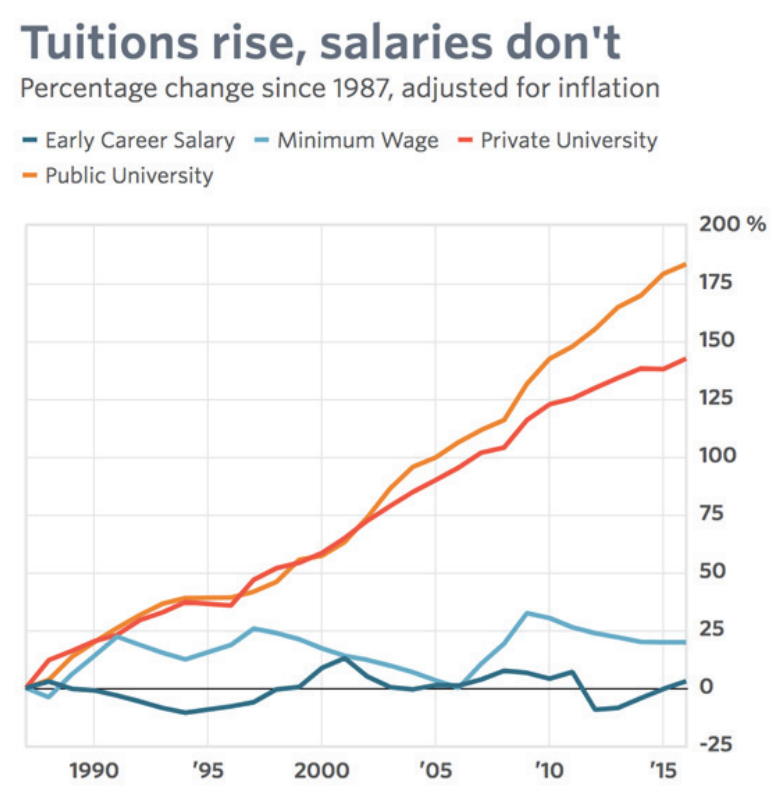

Figure 3: Graph outlining tuition and salary growth (MarketWatch 2017).

\section{3 "Nominal vs Actual Minimum Wage"}

The third section of the work, "Nominal vs Actual Minimum Wage" is a duet for piano and double bass that follows the buying power of the minimum wage from its introduction in 1938 to 2017. The double bass charts the nominal value of the minimum wage over the course of that time while the piano plays the actual value of the minimum wage adjusted for inflation as well as provides harmonic accompaniment. This piece was created by taking a graphical representation of the data (Smith 2019), superimposing on top of it an 8 octave range, and then translating each point on the graph chromatically into the a MIDI roll in Ableton Live (Figure 4). Pitches were then adjusted slightly to help maintain a contour that could be followed by the listener as they track the slow rise of the minimum wage and the oftentimes turbulent changes in its buying power. The piece was not relegated to one key, as I saw the chromatic nature of it helping to reinforce the idea of gradual incrementalism suggested by the slow rise of the minimum wage.

The added harmonic accompaniment provided by the piano is meant to serve as a loose metaphor for the shifting changes in the economy that create the relationship between the piano lead and the double bass. While notes in the melody and bass can linger in place the accompaniment is often moving, either chromatically or in leaps and bounds, drawing contrast between the two and insinuating that the minimum wage, and those who receive it, are often at the mercy of the economic conditions of the time. The instrumentation was chosen due to the wide range of pitches required of each instrument. The double bass presented a mix of rich depth in its lowest pitches and a precarious thinness in its highest register that acted as the perfect metaphor for the strong foundation provided by the minimum wage upon its introduction and the delicate and insufficient place it occupies currently. The rich middle octaves of the piano and its belllike higher register proved an excellent foil for the bass. When presenting this piece visually, it was a decided effort on my part to leave in the ledger lines to help the listener grasp that the higher the music went, the more uncommon it was. 

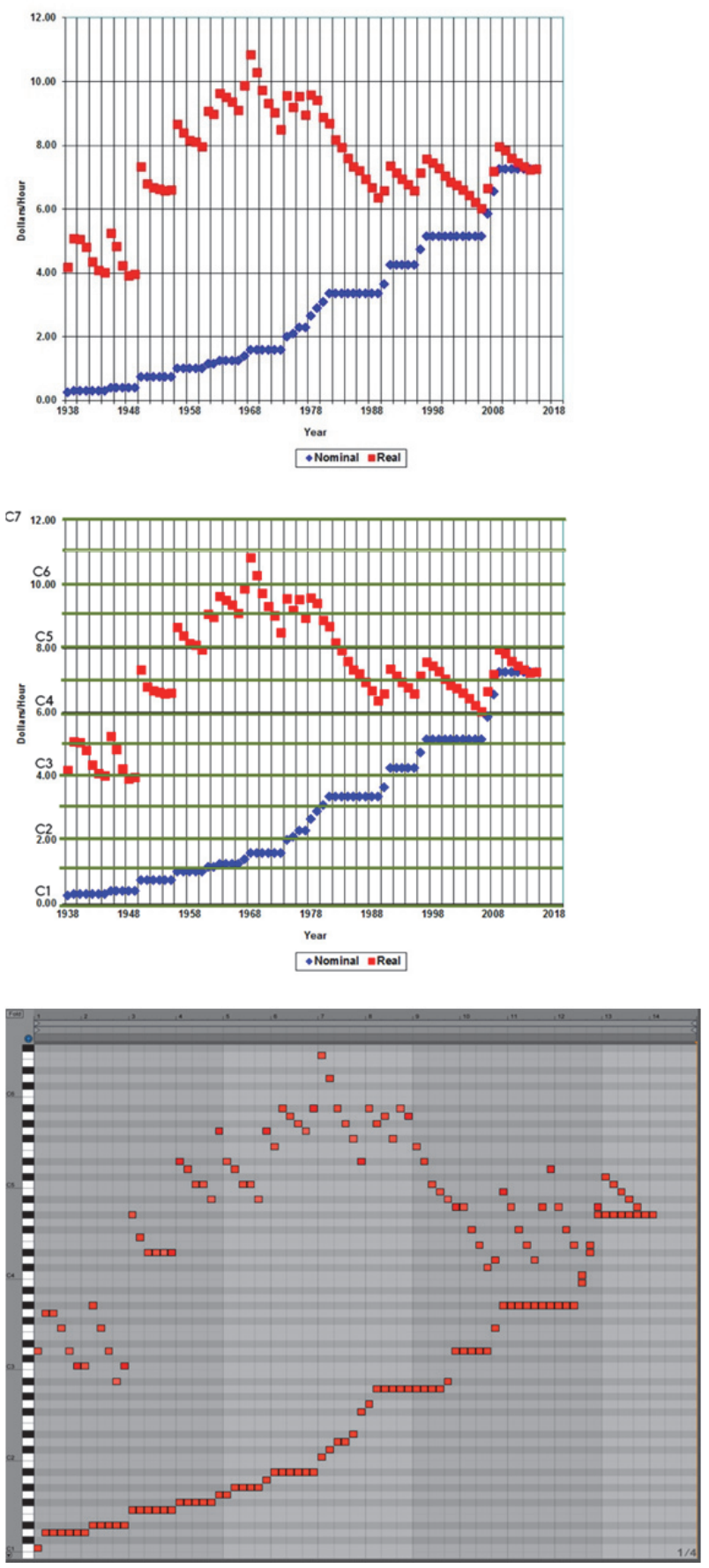

Figure 4: The process of transforming the graph (Smith 2019) into musical notation via the piano roll in Ableton Live.

\section{IMPLEMENTATION}

It was important to me to have student musicians perform on the recordings as the conversation this work surrounds impacts them greatly. Building upon that, it provides in a sense a vehicle of ownership for the students to have a voice in the conversation that exists beyond the boundaries of conventional dialogue. A significant portion of the work is improvisatory in nature and during the recording of each ensemble, where those sections were concerned, I provided no direction to the performers beyond understanding of the structure and motivation for each piece. This was done to ensure integrity of performer's voice and to allow them to "conversate" as an ensemble without interference.

Each ensemble was recorded using a Zoom H6 Handy Recorder with a stereo mic capsule capturing the entire stereo field. Each instrument was also captured with an individual microphone, however when listening back to the recordings the mic capsule provided a more aesthetically pleasing sound. The recordings were looped for the duration of the show over University Galleries integrated sound system. The system is comprised of several 8-inch speakers suspended from the ceiling that are pointed straight down at the concrete floor.

\section{OUTCOMES AND RESPONSES}

The piece was juried into the Student Annual exhibition and was selected by the jurors to receive awards for "Best in Interactive/Digital Media" and "Best in Show" at the opening reception. I participated in and overheard several conversations throughout the opening reception about "A Good Education (Explorations in Data and Music)." Comments varied from serious enquiries about the process of translating the data into music to more humorous remarks about the dissonant nature of several moments. And while this evidence is anecdotal in nature, it was a step towards my goal of facilitating further conversation - a goal that, for the purpose of this project, was far more social than scientific.

Reactions also proved to be rather diverse when exploring sentiments of embodiment towards the music. While the musicians who performed felt a certain sense of connection and ownership to the piece, that feeling could have as much to do with what Paine describes as the "techno-somatic dimension" of performance (2015) as it could with any sense of self-identification towards the music. From discussions with staff members and student employees who spend an extensive amount of time at University Galleries, the music was oftentimes jarring and unbearable at first in its state of constancy but soon became a common, at times unnoticeable, part of their daily routines. These anecdotes provide an almost perfect metaphor for how student debt is often treated within American society; it is a terrible burden, but it is there, and it is something that must be lived with. 


\section{CONCLUSION}

In this paper, I discussed my artwork "A Good Education (Explorations in Data and Music)" and its inclusion in the 2018 Student Annual at University Galleries of Illinois State University. The purpose of this work was to raise awareness of and facilitate conversation around the student debt crisis amongst visitors to University Galleries of Illinois State University. This was done through exploration of the spatial nature of the phrase "in debt" as well through presenting data related to student debt through the novel form of musical scores. Ultimately, visitors to University Galleries experienced a body of turbulent and oftentimes dissonant music that generated spirited conversation about the role and repercussions of student debt within the United States.

\section{REFERENCES}

Board of Governors of the Federal Reserve System (US) (2019)

https://fred.stlouisfed.org/series/SLOAS (retrieved 6 March 2019).

Brookings Institute (2019)

https://www.brookings.edu/wp-

content/uploads/2016/06/Are-College-StudentsBorrowing-Blindly Dec-2014.pdf (retrieved 6 March 2019).

Corness, G. (2008) The Musical Experience through the Lens of Embodiment. Leonardo Music Journal, 21-24.

GoodCall (2019) http://studentdebtcrisis.org/47822/ (retrieved 6 March 2019).
Hermann, T. (2008) Taxonomy and Definitions for Sonification and Auditory Display. Proceedings of the $14^{\text {th }}$ International Conference on Auditory Display. Paris, France, 24-27 June 2008.

Illinois State University (2019).

https://financialaid.illinoisstate.edu/loans/ (retrieved 6 March 2019).

Kramer, G., Walker, B., Bonebright, T., Cook, P., Flowers, J. H., Miner, N. and Neuhoff, J. (2010) Sonification Report: Status of the Field and Research Agenda. Faculty Publications, Department of Psychology, 444. http://digitalcommons.unl.edu/psychfacpub/444 (retrieved 6 March 2019).

MarketWatch News Graphics (2019.

https://www.marketwatch.com/graphics/collegedebt-now-and-then/ (retrieved 6 March 2019).

Merleau-Ponty, M. (2002) Phenomenology of Perception, Routledge Classics, London.

Paine, G. (2015) Interaction as Material: The techno-somatic dimension. Organised Sound, 20(1), 82-89.

Smith, C. (2019)

https://oregonstate.edu/instruct/anth484/minwage.h $\underline{\mathrm{tml}}$ (retrieved 6 March 2019).

U.S. Department of Education (2019) https://www.ed.gov/news/press-releases/nationalstudent-loan-cohort-default-rate-falls (retrieved 6 March 2019).

University Galleries of Illinois State University (2019).

https://galleries.illinoisstate.edu/images/Gallery Di mensions Drafts.pdf (retrieved 6 March 2019). 